(D) Check for updates

Cite this: Dalton Trans., 2018, 47, 1014

Received 13th November 2017, Accepted 8th December 2017

DOI: $10.1039 / c 7 d t 04286 h$

rsc.li/dalton

\section{Neutral two-dimensional organometallic-organic hybrid polymers based on pentaphosphaferrocene, bipyridyl linkers and $\mathrm{CuCl} \uparrow$}

\author{
M. Elsayed Moussa, ${ }^{a}$ B. Attenberger, ${ }^{a}$ E. V. Peresypkina (D) ${ }^{b, c}$ and M. Scheer (D) *a
}

The reaction of the $P_{n}$ ligand complex $\left[C p^{*} \mathrm{Fe}\left(\eta^{5}-\mathrm{P}_{5}\right)\right]\left(1: \mathrm{Cp} *=\eta^{5}-\right.$ $\mathrm{C}_{5} \mathrm{Me}_{5}$ ) with $\mathrm{CuCl}$ in the presence of $4,4^{\prime}$-bipyridine or 1,2-di(4pyridyl)ethylene leads to the formation of three unprecedented neutral 2D organometallic-organic hybrid networks, the constitutional isomers $\left[\mathrm{Cu}_{2} \mathrm{Cl}_{2}\left\{\mathrm{Cp} * \mathrm{Fe}\left(\mu_{3}, \eta^{5: 1: 1}-\mathrm{P}_{5}\right)\right\}\left(\mu, \eta^{1: 1}-\mathrm{C}_{10} \mathrm{H}_{8} \mathrm{~N}_{2}\right)\right]_{n}$ (2 and 3) and the coordination polymer $\left[(\mathrm{CuCl})_{2}\left\{\mathrm{Cp} * \mathrm{Fe}\left(\mu_{3}, \eta^{\text {5:1:1 }}\right.\right.\right.$ $\left.\left.\left.P_{5}\right)\right\}\left(\mu, \eta^{1: 1}-C_{12} H_{10} N_{2}\right)\right]_{n}$ (4) with isomeric square (2 and 3$)$ and honeycomb (4) layer topologies.

In recent years, coordination polymers (CPs) have received great attention due to their high structural diversity associated with a wide variety of chemical and physical properties. ${ }^{1}$ These compounds are generally assembled via the coordination of multitopic organic linkers usually bearing $\mathrm{N}$, O or S donor atoms to metal ions or clusters. ${ }^{2 a-d}$ Due to the lack of using organometallic building blocks in this field, ${ }^{2 e-g}$ our group developed an alternative concept by using organometallic polyphosphorus and polyarsenic ligand complexes with flexible coordination modes as organometallic connectors between metal ions allowing the formation of $1 \mathrm{D}, 2 \mathrm{D}$ and $3 \mathrm{D} \mathrm{CPs}{ }^{3}$ Moreover, one of those polyphosphorus ligand complexes, the tetrahedrane complex $\left[\mathrm{Cp}_{2} \mathrm{Mo}_{2}(\mathrm{CO})_{4}\left(\eta^{2}-\mathrm{P}_{2}\right)\right]\left(\mathrm{Cp}=\mathrm{C}_{5} \mathrm{H}_{5}\right)$ (A) was reacted with $\mathrm{Ag}^{\mathrm{I}}$ and $\mathrm{Cu}^{\mathrm{I}}$ salts of the weakly coordinating anions (WCA) $\mathrm{Al}\left\{\mathrm{OC}\left(\mathrm{CF}_{3}\right)_{3}\right\}_{4}{ }^{-}$, and $\mathrm{FAl}\left\{\mathrm{OC}\left(\mathrm{C}_{6} \mathrm{~F}_{5}\right)\left(\mathrm{C}_{6} \mathrm{~F}_{10}\right)\right\}_{3}{ }^{-}$and the anion $\mathrm{BF}_{4}^{-}$, in the presence of bipyridyl linkers to give unprecedented organometallic-organic hybrid CPs. ${ }^{4}$ However, the cavities formed in the polycationic chains of these networks are tightly occupied by anions, making them rather unattractive candidates for possible applications as for instance gas storage purposes.

\footnotetext{
${ }^{a}$ Institut für Anorganische Chemie der Universität Regensburg, 93040 Regensburg, Germany.E-mail: manfred.scheer@chemie.uni-r.de

${ }^{b}$ Nikolaev Institute of Inorganic Chemistry, Siberian Division of RAS, Acad.

Lavrentyev prosp. 3, 630090 Novosibirsk, Russia

${ }^{c}$ Novosibirsk State University, ul. Pirogova, 2, 630090 Novosibirsk, Russia

$\dagger$ Electronic supplementary information (ESI) available: Details of syntheses, characterization and X-ray crystallography. CCDC 1583104-1583106. For ESI and crystallographic data in CIF or other electronic format see DOI: 10.1039/ c7dt04286h
}

Otherwise, the pentaphosphaferrocene $\left[\mathrm{Cp} * \mathrm{Fe}\left(\eta^{5}-\mathrm{P}_{5}\right)\right]$ (1: $\left.\mathrm{Cp}^{*}=\eta^{5}-\mathrm{C}_{5} \mathrm{Me}_{5}\right)^{5}$ reacts with $\mathrm{Cu}^{\mathrm{I}}$ halides depending on the reaction conditions to different $1 \mathrm{D}$ and $2 \mathrm{D}$ polymers, ${ }^{3 e, h, i}$ nano-sized fullerene-like spherical aggregates ${ }^{6}$ and a huge organometallic-based capsule. ${ }^{7}$ We therefore became interested in exploring the possibility to establish a novel class of organometallic-organic CPs using the cyclo- $\mathrm{P}_{5}$ ligand complex 1 in combination with metal cations and organic linkers. Moreover, we targeted the synthesis of neutral hybrid networks instead of the already developed synthesis of cationic frameworks from the $\mathrm{P}_{2}$ ligand complex A. Obviously, the $\mathrm{Ag}^{\mathrm{I}}$ or $\mathrm{Cu}^{\mathrm{I}}$ salts of WCA are no suitable candidates for such purposes as the voids in the resulting structures can be occupied by the counterions. Therefore, the use of coordinating anions such as $\mathrm{Cl}^{-}$could be useful, as they can coordinate much more strongly to the metal centers leading to targeted networks with substantial (non-occupied) porosity. Herein, we report on the synthesis of the first pentaphosphaferrocene-based 2D neutral polymeric compounds. These unprecedented hybrid CPs are obtained from a three-component reaction of the pentaphosphaferrocene 1 in combination with the bipyridyl linkers 4,4'-bipyridine or 1,2-di(4-pyridyl)ethylene and CuCl. To the best of our knowledge, no other neutral organometallicorganic hybrid CPs has been yet reported.

In a first approach, the cyclo- $\mathrm{P}_{5}$ ligand complex $\mathbf{1}$ was reacted with $\mathrm{CuCl}$ and 4,4'-bipyridine in a $1: 2: 1$ stoichiometry. This reaction afforded the products 2 or 3 as brown crystals in excellent yields ( $84 \%$ and $75 \%$, respectively, see the ESI $\dagger$ ), depending on the used solvent mixture. Compound 2 is obtained when a $\mathrm{CH}_{2} \mathrm{Cl}_{2}$ solution of $\mathbf{1}$ is slowly added to a $\mathrm{CH}_{3} \mathrm{CN}: \mathrm{CH}_{2} \mathrm{Cl}_{2}(1: 1)$ solution mixture of $\mathrm{CuCl}$ and 4,4'-bipyridine, while compound 3 is isolated when a toluene solution of 1 is added to a $\mathrm{CH}_{3} \mathrm{CN}: \mathrm{CH}_{2} \mathrm{Cl}_{2}(1: 1)$ solution mixture of $\mathrm{CuCl}$ and 4,4'-bipyridine. The compounds 2 and 3, respectively, crystallize at room temperature from $n$-pentane (2) or toluene (3) diffusion into the solutions of the crude reaction mixtures, and their structures were examined by X-ray crystallography (see the ESI†). Their crystal structures reveal that the assemblies 2 and 3 represent unprecedented neutral 2D organo- 
a)



b)

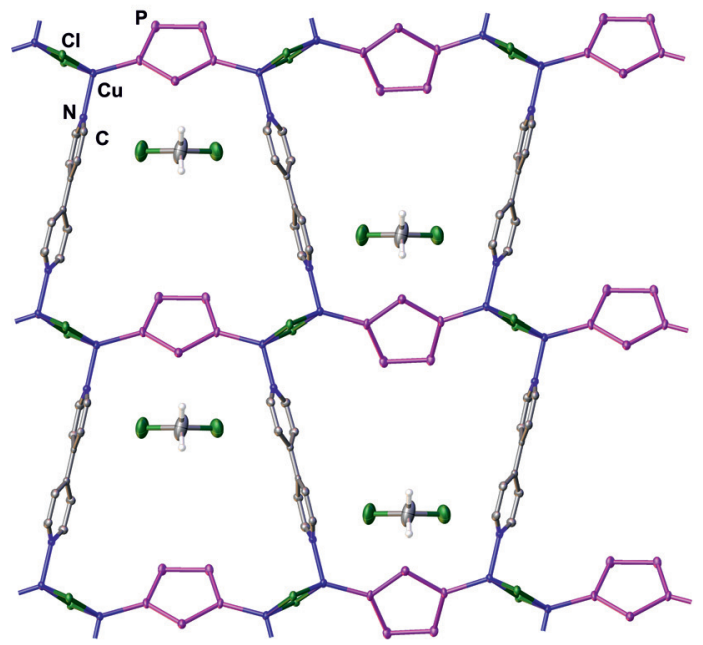

Fig. 1 Fragments of single planar square layers in the 2D neutral polymeric networks (a) 2 and (b) 3 representing constitutional isomerism; $\mathrm{Cp}^{*} \mathrm{FeP}$ are shown as cyclo- $\mathrm{P}_{5}$ fragments; $\mathrm{H}$ atoms (except for the partially entrapped solvent molecules) are omitted for clarity.

metallic-organic hybrid polymers with the general formula $\left[\mathrm{Cu}_{2} \mathrm{Cl}_{2}\left\{\mathrm{Cp}^{*} \mathrm{Fe}\left(\mu_{3}, \eta^{5: 1: 1}-\mathrm{P}_{5}\right)\right\}\left(\mu, \eta^{1: 1}-\mathrm{C}_{10} \mathrm{H}_{8} \mathrm{~N}_{2}\right)\right]_{n}$ (Fig. 1).

Interestingly, the polymers 2 and 3 are constitutional isomers with a planar layered constitution providing different types of rings in the 2D polymeric arrangements (Fig. 1). Small (with a maximum dimension of $1.14 \mathrm{~nm})^{8}$ and large (with a maximum dimension of $1.51 \mathrm{~nm})^{8}$ rectangular rings in 2 and one-type trapezoidal rings (with a maximum dimension $1.34 \mathrm{~nm})^{8}$ in 3 appear, depending on the coordination of the 4,4'-bipyridine linkers to one or the other $\mathrm{Cu}$ ion of the $\mathrm{Cu}_{2} \mathrm{Cl}_{2}$ dimer. In both kinds of these isomeric square (sql) layers 2 and 3 , two $\left[\mathrm{Cu}_{2} \mathrm{Cl}_{2}\right]$ four-membered rings are bridged by a pentaphosphaferrocene molecule with the cyclo- $\mathrm{P}_{5}$ ligand adopting the 1,3-bridging mode and forming infinite chains. These chains are in turn connected via the 4,4'-bipyridine linkers coordinated to the copper atoms to give the final $2 \mathrm{D}$ structures. Consequently, each copper ion in $\mathbf{2}$ and $\mathbf{3}$ possesses a distorted tetrahedral coordination geometry $(2 \mathrm{Cl}+1 \mathrm{P}+1 \mathrm{~N})$. The 4, $4^{\prime}-$ bipyridine linkers in the polymers 2 and 3 are well separated from each other (from $\sim 7.9 \AA$ in 2 up to $\sim 11.8 \AA$ in 3 ) and therefore do not show any intramolecular $\pi-\pi$ stacking interactions. The $\mathrm{P}-\mathrm{P}$ bond lengths in 2 and 3 are in the range between 2.101(3) and 2.120(5) ^, which is essentially consistent with those of the non-coordinated complex $1(2.117 \AA){ }^{9}$ The $\mathrm{Cu}-\mathrm{P}$ bond lengths in 2 and 3 are in the range between 2.173(5) and 2.184(5) A.

In the crystal structure of network 2 , one $n$-pentane molecule is embedded in each of the small cavities of the rings and only partially occupies these cavities. These guest molecules are stabilized by $\mathrm{CH} \cdots \pi$ interactions between the methylene hydrogens of the $n$-pentane molecules and the $\pi$ clouds of the pyridyl moieties of the $4,4^{\prime}$-bipyridine linker ( $\mathrm{CH} \cdots \pi$ (pyridyl centroid) distance is 3.097(9) $\AA$ ). Similarly, one $\mathrm{CH}_{2} \mathrm{Cl}_{2}$ molecule is partially embedded in each of the cavities of the rings of 3 . These $\mathrm{CH}_{2} \mathrm{Cl}_{2}$ molecules are stabilized by the $\mathrm{Cl} \cdots \pi$ interactions between the chlorine atoms of the $\mathrm{CH}_{2} \mathrm{Cl}_{2}$ molecules and the $\pi$ clouds of the pyridyl moieties of the 4,4'-bipyridine linker

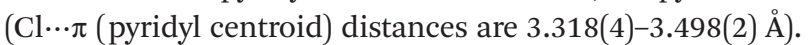

These results motivated us to expand these investigations by using the slightly longer linker 1,2-di(4-pyridyl)ethylene. The reaction of $\mathbf{1}$ with $\mathrm{CuCl}$ and 1,2-di(4-pyridyl)ethylene in a $1: 2: 1$ stoichiometry leads to the formation of compound 4 as brown blocks in moderate yield (40\%, see the ESI $\dagger$ ) suitable for single crystal X-ray structure analysis. Compound 4 is a novel neutral 2D organometallic-organic hybrid polymer of the formula $\left[(\mathrm{CuCl})_{2}\left\{\mathrm{Cp} * \mathrm{Fe}\left(\mu_{3}, \eta^{5: 1: 1}-\mathrm{P}_{5}\right)\right\}_{2}\left(\mu, \eta^{1: 1}-\mathrm{C}_{12} \mathrm{H}_{10} \mathrm{~N}_{2}\right)\right]_{n}$. The stoichiometry of the building blocks in the resulting polymer 4 is different from that of the used starting materials. Polymer 4 is also obtained in a similar yield upon using a $2: 2: 1$ stoichiometric ratio of $\mathbf{1}, \mathrm{CuCl}$ and 1,2-di(4-pyridyl) ethylene. In 4 , the $[\mathrm{CuCl}]$ units are connected by the organic linkers in contrast to the $\left[\mathrm{Cu}_{2} \mathrm{Cl}_{2}\right]$ rings in 2 and 3 and therefore give honeycomb layers (hcb topology) (Fig. 2). Owing to the doubled stoichiometric amount of pentaphosphaferrocene spacers in $\mathbf{4}$ as compared to $\mathbf{2}$ and 3, larger rings are formed with a maximum dimension of $2.24 \mathrm{~nm}$, which are left empty in this solvent-free structure. ${ }^{8}$ As a result, $\pi-\pi$ stacking occurs between the almost parallel $\mathrm{Cp}^{*}$ ligands of $\mathbf{1}$ and the planar 1,2-di(4-pyridyl)ethylene linkers with interplanar distances of 3.47-3.54 $\AA$ (cf. ESI $\dagger$ ), in contrast to the polymers 2 and 3 where no such $\pi-\pi$ stacking is observed.

The $\mathrm{P}-\mathrm{P}$ bond lengths in 4 are in the range between 2.105 (2) and 2.115(8) $\AA$, comparable to those of the non-coordinated ligand 1 and the polymers 2 and 3 . The $\mathrm{Cu}-\mathrm{P}$ bond in $\mathbf{4}(2.210$ (9) $\AA$ ) is slightly elongated compared to those in 2 and 3.

The compounds $\mathbf{2 - 4}$ are only very slightly soluble in donor solvents such as $\mathrm{CH}_{3} \mathrm{CN}$ but completely insoluble in other common organic solvents such as $\mathrm{CH}_{2} \mathrm{Cl}_{2}$, THF and $n$-pentane. Their room temperature ${ }^{31} \mathrm{P}\left\{{ }^{1} \mathrm{H}\right\}$ NMR spectra in $\mathrm{CD}_{3} \mathrm{CN}$ exhibit single signals at $c a$. $151 \mathrm{ppm}$, which are very similar to that of the free ligand complex $1(152.2 \mathrm{ppm})^{3 d}$ revealing a degradation of the polymeric structure in solution. 


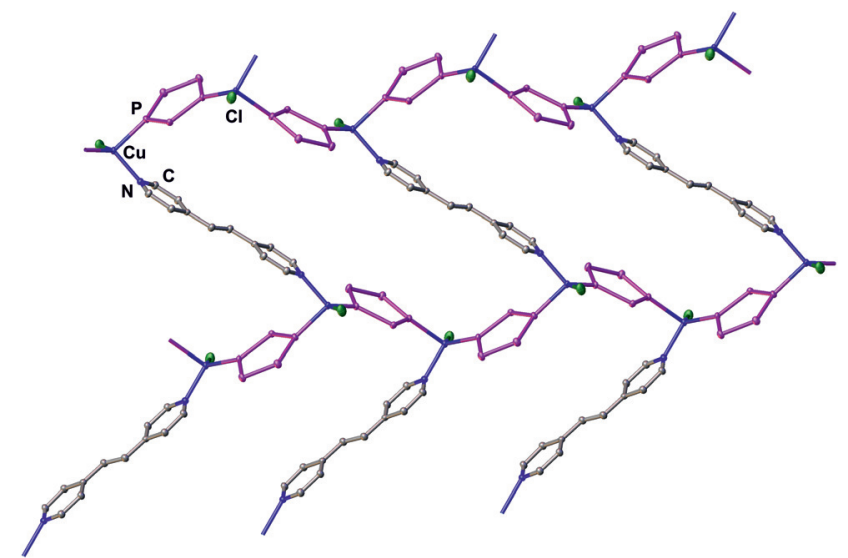

Fig. 2 Fragment of a single layer in the neutral 2D polymeric network 4; $\mathrm{Cp}^{\star} \mathrm{FeP}_{5}$ are represented as cyclo- $\mathrm{P}_{5}$ fragments; $\mathrm{H}$ atoms are omitted for clarity.

\section{Conclusions}

In conclusion, we have shown the possibility of using the pentaphosphaferrocene ligand complex (1) in a three- component reaction with $\mathrm{CuCl}$ and the bipyridyl linkers 4,4'-bipyridine or 1,2-di(4-pyridyl)ethylene to synthesize a new class of hybrid CPs. This new reaction allows the synthesis of three unique neutral 2D organometallic-organic hybrid CPs with different layer topologies. These results show the importance of this novel method using $\mathrm{P}_{n}$ ligand complexes for the synthesis of a new class of hybrid CPs. For the first time, the use of $\mathrm{CuCl}$ allows the approach to unprecedented neutral organometallic-organic hybrid CPs in which the meshes are only occupied by solvent molecules, in contrast to previously obtained cationic hybrid CPs with the anions in the voids. This finding opens up a new chapter in this chemistry. Current investigations involve the use of multitopic pyridinebased linkers to synthesize neutral 3D organometallic-organic hybrid networks as an analogy to the very well-studied class of neutral 3D metal organic frameworks (MOFs).

\section{Conflicts of interest}

There are no conflicts to declare.

\section{Acknowledgements}

This work was comprehensively supported by the European Research Council by Grant ERC-2013-AdG 339072. The COST action CM 1302 (SIPs) is gratefully acknowledged.

\section{Notes and references}

1 (a) A. Winter and U. S. Schubert, Chem. Soc. Rev., 2016, 45, 5311; (b) X. Zhang, W. Wang, Z. Hu, G. Wang and K. Uvdal,
Coord. Chem. Rev., 2015, 284, 206; (c) C. He, D. Liu and W. Lin, Chem. Rev., 2015, 115, 11079; (d) L. Carlucci, G. Ciani, D. M. Proserpio, T. G. Mitina and V. A. Blatov, Chem. Rev., 2014, 114, 7557; (e) R. Haldar and T. K. Maji, Angew. Chem., Int. Ed., 2014, 44, 11772; $(f)$ T. R. Cook, Y.-R. Zheng and P. J. Stang, Chem. Rev., 2013, 113, 734; (g) W. L. Leong and J. J. Vittal, Chem. Rev., 2011, 111, 688.

2 (a) E. Lee, H. Ju, S. Kim, K.-M. Park and S. S. Lee, Cryst. Growth Des., 2015, 15, 5427; (b) E. Lee, K.-M. Park, M. Ikeda, S. Kuwahara, Y. Habata and S. S. Lee, Inorg. Chem., 2015, 54, 5372; (c) R. Charkabarty, P. S. Mukherjee and P. J. Stang, Chem. Rev., 2011, 111, 6810; (d) F. A. Cotton, E. V. Dikarev and M. A. Petrukhina, Angew. Chem., Int. Ed., 2001, 40, 1521; (e) P. J. Stang, B. Olenyuk, J. Fan and A. M. Arif, Organometallics, 1996, 15, 904; $(f)$ K. Škoch, I. Císařová and P. Štěpnička, Inorg. Chem., 2014, 53, 568; $(g)$ K. Škoch, I. Císařová, J. Schulz, U. Siemeling and P. Štěpnička, Dalton Trans., 2017, 46, 10339.

3 Selected publications: (a) M. E. Moussa, M. Fleishmann, E. V. Peresypkina, L. Dütsch, M. Seidl, G. Balázs and M. Scheer, Eur. J. Inorg. Chem., 2017, 25, 3222; (b) C. Heindl, A. Kuntz, E. V. Peresypkina, A. V. Virovets, M. Zabel, D. Lüdeker, G. Brunklaus and M. Scheer, Dalton Trans., 2015, 44, 6502; (c) C. Heindl, E. V. Peresypkina, A. V. Virovets, V. Y. Komarov and M. Scheer, Dalton Trans., 2015, 44, 10245; (d) M. Fleishmann, S. Welsch, E. V. Peresypkina, A. V. Virovets and M. Scheer, Chem. - Eur. J., 2015, 21, 14332; (e) F. Dielmann, C. Heindl, F. Hastreiter, E. V. Peresypkina, A. V. Virovets, R. M. Gschwind and M. Scheer, Angew. Chem., Int. Ed., 2014, 53, 13605; (f) E.-M. Rummel, M. Eckhardt, M. Bodensteiner, E. V. Peresypkina, W. Kremer, C. Gröger and M. Scheer, Eur. J. Inorg. Chem., 2014, 10, 1625; ( $g$ ) H. Krauss, G. Balázs, M. Bodensteiner and M. Scheer, Chem. Sci., 2010, 1, 337; (h) M. Scheer, L. J. Gregoriades, A. V. Virovets, W. Kunz, R. Neueder and I. Krossing, Angew. Chem., Int. Ed., 2006, 45, 5689; (i) J. Bai, A. V. Virovets and M. Scheer, Angew. Chem., Int. Ed., 2002, 41, 1737; $(j)$ J. Bai, E. Leiner and M. Scheer, Angew. Chem., Int. Ed., 2002, 41, 783.

4 (a) M. E. Moussa, M. Seidl, G. Balazs, A. V. Virovets, B. Attenberger, A. Schreiner and M. Scheer, Chem. - Eur. J., 2017, 16199; (b) M. E. Moussa, B. Attenberger, M. Fleischmann, A. Schreiner and M. Scheer, Eur. J. Inorg. Chem., 2016, 28, 4538; (c) M. Elsayed Moussa, B. Attenberger, E. V. Peresypkina, M. Fleischmann, G. Balázs and M. Scheer, Chem. Commun., 2016, 52, 10004; (d) B. Attenberger, E. V. Peresypkina and M. Scheer, Inorg. Chem., 2015, 54, 7021; (e) B. Attenberger, S. Welsch, M. Zabel, E. Peresypkina and M. Scheer, Angew. Chem., Int. Ed., 2011, 50, 11516.

5 (a) O. J. Scherer and T. Brück, Angew. Chem., Int. Ed. Engl., 1987, 26, 59; (b) O. J. Scherer, T. Brück and G. Wolmershäuser, Chem. Ber., 1988, 121, 935.

6 Selected articles: (a) E. V. Peresypkina, C. Heindl, A. V. Virovets and M. Scheer, Struct. Bonding, 2016, 174, 321; (b) C. Heindl, S. Reisinger, C. Schwarzmaier, L. Rummel, 
A. V. Virovets, E. V. Peresypkina and M. Scheer, Eur. J. Inorg. Chem., 2016, 5, 743; (c) C. Heindl, E. V. Peresypkina, D. Lüdeker, G. Brunklaus, A. V. Virovets and M. Scheer, Chem. - Eur. J., 2016, 22, 2599; (d) C. Heindl, E. V. Peresypkina, A. V. Virovets, W. Kremer and M. Scheer, J. Am. Chem. Soc., 2015, 137, 10938; (e) F. Dielmann, C. Heindl, F. Hastreiter, E. V. Peresypkina, A. V. Virovets, R. M. Gschwind and M. Scheer, Angew. Chem., 2014, 126, 13823, (Angew. Chem. Int. Ed., 2014, 53, 13605); (f) M. Scheer, A. Schindler, R. Merkle, B. P. Johnson, M. Linseis, R. Winter, C. E. Anson and A. V. Virovets, J. Am. Chem. Soc., 2007, 129, 13386; (g) J. Bai, A. V. Virovets and
M. Scheer, Science, 2003, 300, 781; (h) C. Heindl, E. Peresypkina, A. V. Virovets, I. S. Bushmarinov, M. G. Medvedev, B. Krämer, B. Dittrich and M. Scheer, Angew. Chem., Int. Ed., 2017, 43, 1323713243.

7 S. Welsch, C. Groeger, M. Sierka and M. Scheer, Angew. Chem., Int. Ed., 2011, 50, 1435.

8 Calculated from the largest distance between the $\mathrm{Cu}^{+}$ions minus the doubled ionic radius of $\mathrm{Cu}^{+}$for the coordination number 4 (0.74 $)$.

9 R. Blom, T. Brück and O. J. Scherer, Acta Chem. Scand., 1989, 43, 458 . 